\title{
O punctum como ausência na coleção perseverança: um percurso do olhar através do conceito de representação
}

\author{
ANDERSON DIEGO ALMEIDA \\ FRANCISCO MARSHALL
}

Resumo

A partir da perspectiva conceitual sobre o punctum, elaborada por Roland Barthes, em A Câmara Clara, o artigo discorre sobre as suas múltiplas possibilidades de interpretação, e uma delas é o pungir da ausência. A primeira proposta é estabelecer um diálogo entre o conceito proposto por Barthes e Eliane Chiron, e o de representação, elaborado por alguns autores, dentre eles E. H. Gombrich. A segunda é analisar o punctum e sua aplicabilidade a partir da análise de um dos objetos da Coleção Perseverança', a Bolsa tipo Capanga ${ }^{2}$. Ademais, a narrativa construída mostra a possibilidade do conceito barthesiano para outras manifestações humanas além da fotografia. 


\title{
Punctum as absence in coleção perse- verança: a looking route through the concept of representation
}

\author{
ANDERSON DIEGO ALMEIDA \\ FRANCISCO MARSHALL
}

\section{Abstract}

From the conceptual perspective on punctum elaborated by Roland Barthes in The Clara Chamber, the paper discusses its multiple possibilities of interpretation, and one of them is the punch of absence. The first proposal is to establish a dialogue between the concept proposed by Barthes and Eliane Chiron, and that of representation, elaborated by some authors, among them E. H. Gombrich. The second is to analyze the puctum and its applicability from the analysis of one of the objects of Coleção Perseverança, the Bolsa tipo Capanga. Furthermore, the constructed narrative shows the possibility of the barthesian concept to other human manifestations besides photography. 


\section{El punctum como ausencia en la colección persecerancia: un recorrido de la mirada através del concepto de representación}

\section{ANDERSON DIEGO ALMEIDA \\ FRANCISCO MARSHALL}

\section{Resumen}

A partir de la perspectiva conceptual sobre el punctum, elaborado por Roland Barthes, en la Cámara Clara, el artículo diserta sobre sus múltiples posibilidades de interpretación, y una de ellas es el castigo de la ausencia. La primera propuesta es establecer un diálogo entre el concepto propuesto por Barthes y Eliane Chiron y el de Representación, elaborado por algunos autores, entre ellos E. H. Gombrich. La segunda es analizar el puctum y su aplicabilidad a partir del análisis de uno de los objetos de la Colección Perseverança, la "Bolsa tipo Capanga". Sin embargo, la narrativa construida muestra la posibilidad del concepto barthesiano para otras manifestaciones humanas además de la fotografía.

Palabras clave:

Punctum, representación, Colección Perseverança 


\section{O primeiro olhar}

Nesse espaço habitualmente unário, às vezes (mas infelizmente, com raridade) um "detalhe" me atrai. Sinto que basta a sua presença para mudar minha leitura (...) (BARTHES, 1984, p. 68).

No livro A câmara clara, de 1980, Roland Barthes discorre sobre dois conceitos co-presentes que ele identifica nas fotografias: o studium e o punctum.

O primeiro, studium, é percebido culturalmente e, com isso, gera uma interpretação da foto a partir do conhecimento prévio do spectator sobre o mundo. O segundo, punctum, diferentemente, se lança sobre nós, de forma insistente. Como escreve Barthes (1984, p. 46), "não sou eu que vou buscá-lo (como invisto com minha consciência soberana o campo do studium), é ele que parte da cena, como uma flecha, e vem me transpassar".

Esses dois conceitos mencionados pelo autor permitem, em consequência, uma apreensão diferente por parte de quem observa uma fotografia. O studium gera um interesse racional que predispõe o intérprete a uma reflexão e a uma análise, enquanto o punctum cria um estado emocional em quem o experiencia, despertando, assim, uma reflexão a partir da memória e da representação - o que nos leva a perceber outros contextos, depois de pungido, e a representar as sensações a partir do detalhe, no qual fomos fisgados.

Mesmo que Barthes (1984) relate os dois conceitos como co-presentes em fotos, podemos perceber que é a constatação da existência específica do punctum que move o texto e instiga o autor. Portanto, é partindo deste pressuposto que este artigo envereda-se pela construção de uma narrativa na identificação 
do punctum a partir da ausência - o sentido de não existência, algo que foi tirado. Sob esse viés, este punctum encontra-se na falta de uma das medalhas que compõem a Bolsa tipo Capaganga. Esta peça faz parte da Coleção Perseverança, catalogada como parte da indumentária de orixás.

Este artigo constrói uma nova possibilidade de leitura dos conceitos barthesianos, para além da fotografia, especificamente do punctum, mostrando sua transdisciplinaridade e suas possibilidades de uso em novos contextos. A seguir, apresentamos um breve relato sobre o uso dos conceitos de punctum, studium, representação e uma análise do punctum a partir da ausência na Bolsa tipo Capanga.

\section{Sobre o punctum: o conceito do pungir}

Produzir conceitos é, antes de tudo, uma atividade criadora que permite inventar novas maneiras de pensar, de sentir, de ver (conceber, perceber), de compreender o incompreensível (HARDY-VALLÉE, 2013, p. 10).

Ao perguntar o que é um conceito, Benoit Hardy-Vallée (2013) apresenta as diferentes concepções de conceito em função dos campos do saber, das teorias, dos discursos. $\mathrm{O}$ "que é?" se desdobra rapidamente em "como funcionam os conceitos?", em "para que servem os conceitos?", e, sobretudo, em "como se constroem os conceitos?". Conceitos são universais abstratos que aplicam a representação de propriedades invariantes de uma categoria a objetos particulares em função de um critério.

Um conceito é um conhecimento mais geral aplicado a um objeto ou a uma situação particular: representa uma categoria de objetos, de eventos ou de situações e pode ser expresso por uma ou mais de uma palavra. Para alguns, essa representação é mental; para outros, ela é linguística e pública. O conceito é a unidade primeira do pensamento e do conhecimento: só pensamos e conhecemos na medida em que manipulamos conceitos. Neste sentido, como diz Hardy-Vallée (2013, p. 10) "produzir conceitos é, antes de tudo, uma atividade criadora que permite inventar novas maneiras de pensar, de sentir, de ver (conceber, perceber), de compreender o incompreensível".

A partir da perspectiva conceitual, apresentada anteriormente, e com a finalidade de uma melhor compreensão sobre a função do punctum neste artigo, necessita-se, antes, 
entender o conceito de studium, antagônico ao primeiro, sob o viés da abordagem cultural, necessária neste estudo, para corroborar com a contextualização da representação próxima ao que Barthes define como a sensação do pungir.

Sobre o studium, Barthes (1984, p. 44) escreve: "percebo [...] em função de meu saber, de minha cultura [...]", e complementa que "[...] é culturalmente [...] que participo das figuras, das caras, dos gestos, dos cenários, das ações" (BARTHES, 1984, p. 46).

Depreende-se por essas duas frases que a percepção do studium passa pela decodificação dos signos presentes em uma fotografia em função do conhecimento prévio de quem observa a foto. Um signo, convencionado como um símbolo, necessita que o intérprete conheça seu código para sua interpretação. É pelo teor convencional que há entre signo e objeto representado que se gera a representação.

Segundo Lévi-Strauss (apud VELHO; VIVEIROS DE CASTRO, 1980, p. 17), a cultura é "[...] um conjunto complexo de códigos que asseguram a ação coletiva de um grupo". Os indivíduos, ao crescerem dentro de uma determinada cultura, aprendem seus códigos, os internalizam e passam a interpretar o mundo a partir dessas bases. Assim, exemplificando, para uma mesma foto, pode haver níveis diferentes de interpretação, dependendo do conhecimento cultural que o indivíduo tenha.

Essa variedade de análise dependerá não apenas da diferença de formação entre intérpretes distintos: a capacidade de interpretação também pode mudar ao longo do tempo para um mesmo intérprete. Vale a reflexão: quem já não viu com outros olhos livros, filmes e fotografias, depois de anos de terem tido com eles um primeiro contato? Ao lermos o exemplo citado por Barthes (1984, p. 86-87) da foto da rainha Vitória montada a cavalo, é necessário que se conheça a história da Inglaterra, a rainha, sua época, seus hábitos, as vestimentas do século XIX, para que se faça a interpretação do studium.

Compreender o studium, portanto, passa pela decodificação do pensamento racional. É a partir da expressão do signo, pensamento, conceito, cultura e razão, que se infere o studium de uma fotografia. Como escreve Barthes (2015, p. 31):

Reconhecer o studium é fatalmente encontrar as intenções do fotógrafo, entrar em harmonia com elas, aprová-las, desaprová-las, mas sempre compreendê-las, discuti-las em mim mesmo, pois a cultura (com que tem a ver o studium) é um contrato feito entre os criadores e os consumidores. 
Barthes enfatiza que escolheu o nome latino studium para esse conceito porque o entende como "[...] a aplicação a uma coisa, o gosto por alguém, uma espécie de investimento geral, ardoroso, é verdade, mas sem acuidade particular" (BARTHES, 2015, p. 29).

A generalidade presente no studium é de ordem diferente da singularidade do outro conceito que ele denomina punctum: este, ele argumenta, "[...] é também picada, pequeno buraco, pequena mancha, pequeno corte, e também lance de dados. O punctum de uma foto é esse acaso que, nela, me punge [...]" (BARTHES, 2015, p. 29). Portanto, "O studium está, em definitivo, sempre codificado, o punctum não [...]" (BARTHES, 1984, p. 80).

Os dois elementos encontram-se imbricados na foto assim como em outras manifestações do mundo. O primeiro elemento permite o pensamento racional, organizador e analítico. O segundo, alheio ao verbal e tantas vezes deixado de lado pela dificuldade de nossa mente de lidar com o indizível, possibilita o sentimento. "Há, assim, uma espécie de resíduo de mundo, algo não recolhível pela linguagem, na sua expressão lógica, algo que é por ela desdenhado porque estranho à sua própria estrutura e interesse [...]" (IBRI, 2008, p. 232).

A concepção de Barthes (1984, p. 71) de que "esse punctum agita [...] uma grande benevolência, quase um enternecimento" deixa transparecer a forma de apreensão possível desse segundo elemento. Para apreendê-lo, portanto, deve-se permitir um estado de contemplação e de comunhão próprios da primeira categoria. A sensação de presentidade, citada por Peirce (1958), também pode ser percebida na expressão da experiência de Barthes quando atingido por um punctum: "Esse alguma coisa deu um estalo, provocou em mim um pequeno abalo, um satori, a passagem de um vazio [...]" (BARTHES, 1984, p. 77).

Para construir o percurso do punctum dentro deste artigo, é importante o entendimento de que sua ampliação, para outras artes além da fotografia, dá-se com Eliane Chiron em Ao $7^{\circ} \mathrm{X}$ : trivium com centauro, estrelas e dançarinas (1996), em que a autora propõe-se a desvendar inesperados significantes presentes no processo de criação artística com enfoque naquele que cria: $\mathrm{o}$ artista.

A abordagem de Chiron (1996) está fundamentada em elementos da mitologia, representados por um X, e nas encruzilhadas onde se entrecruzam o centauro, as estrelas e as dançarinas. A partir dos vários X, duas linhas sobrepostas que 
não se tocam e onde no intercruzamento permanece a questão, o vazio, reside a construção da "atmosfera do punctum".

Chiron (1996, p. 8-12) afirma o X como enigma dele mesmo:

Tudo que se encontra deslocado, rejeitado fora de categorias, fora de pontos fixos, dos lugares comuns e dos caminhos sinalizados; o que se sustenta sob as aparências, sob as superfícies onde desaparece a claridade da evidência; o que é confiado, [...]. Tem-se o X como alvo selado na obra em processo; o X como trajeto e quiasma (da obra); também o $\mathrm{X}$ como horizonte [da obra] "esta desconhecida que assegura a promoção ontológica do seu objeto"; o X como paradigma [do criador], estrangeiro a si mesmo; o X como assinatura [do artista]: "antes de reportar a uma marca de anonimato, assinar X manifesta uma identidade plural, de muitas maneiras, onde ela se define como anterioridade e alteridade. [...] Cruzamento de natureza e de cultura. Hibridação, enxerto, mestiçagem". O X como cruzamento [do centauro, das estrelas e das dançarinas], "ciclo podendo ser multiplicado"; "X, a figura do artista, entrecruzamento de múltiplas probabilidades, de um nome infinito de domínios possíveis.

Nessa visão, o punctum não é fixo, nem estável, é móvel e atualizado na visão do espectador.

Ao investigar o punctum, como o que está no meio de duas ou mais possibilidades, Chiron (1996, p. 18) contextualiza a topologia na obra de Degas:

De uma parte, a justaposição das bandas de papel afirmam [sic] as duas dimensões do suporte: ela estabelece entre seus diferentes fragmentos relações topológicas de vizinhança e de envolvimento. (...) Casando um espaço topológico em expansão a um espaço perspectivo ascendente e descentrado, Degas concilia dois meios contraditórios de tornar visível um novo tipo de dimensão temporal. Efetivamente, a presença simultânea de duas categorias de espaços reforça esse efeito de instantaneidade que o pintor buscava.

Tendo como exemplo as obras de Degas, Chiron (1996, p. 19) trata do movimento vertical na base como "o esquema 'verticalizante', consubstancial ao esquema de elevação, indissociável do nível horizontal. Esta horizontalidade ordena a percepção visual, o élan vertical a qual se subordina a nossa visão". 
Enquanto Barthes concentra-se na fotografia, na visão do espectador e situa o punctum em um detalhe específico, único, da ordem do noema do "isso-foi"; Chiron leva o punctum para outras artes a partir do processo de criação artística, fixando o punctum no vazio, no entre.

Ao corroborar com Chiron, Icleia Cattani (2005, p. 24-25) menciona que este punctum está

entre dois pontos, entre dois núcleos, descentrado - correspondendo não ao círculo, mas a [sic] elipse que possui dois centros e que é a forma barroca por excelência, ou seja, vinculada a [sic] ambiguidade, à ambivalência, à tensão.

O conceito, segundo Chiron (1996, p. 25) é da ordem do "isso é": "Em algum ponto desse vazio, encontra-se o punctum, ali onde o olhar se perde (como no cruzamento das linhas que compõe $[\mathrm{m}]$ o símbolo do infinito)".

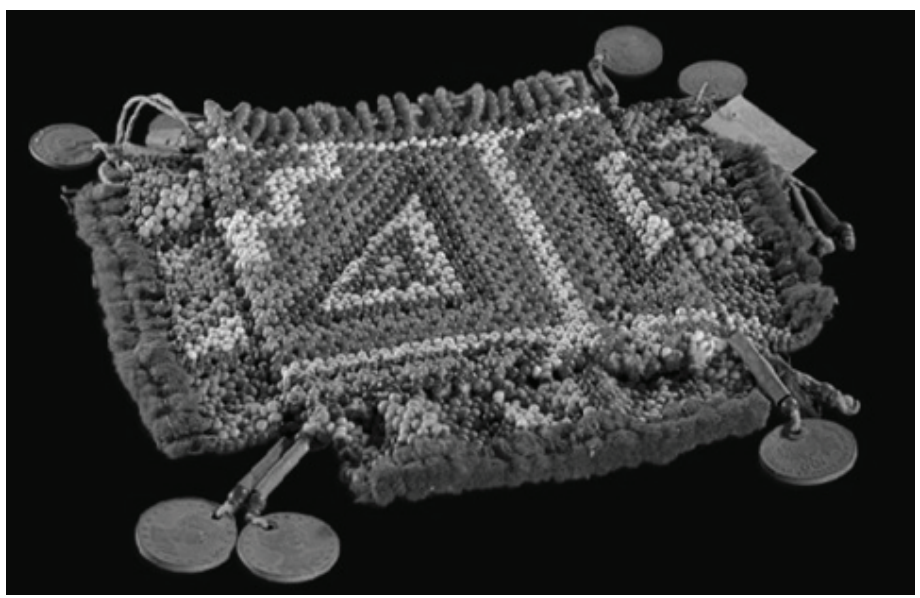

Bolsa Tipo Capanga - Coleção Perseverança.

Fonte: arquivo pessoal, s/d.

\section{Bolsa Tipo Capanga: o punctum como ausência e sua representação}

Em algum ponto desse vazio, encontra-se o punctum, ali onde o olhar se perde (como no cruzamento das linhas que compõe [m] o símbolo do infinito) (CHIRON, 1996, p. 25).

Tomando o primeiro punctum como o punctum de Barthes (1984), aquele aplicado à fotografia; e o segundo punctum, como o punctum de Chiron (1996), que é aquele expandido 
O punctum na ausência da moeda Fonte: arquivo pessoal, s/d. às demais categorias artísticas, a Bolsa tipo Capanga, parte da Coleção Perseverança, apresenta seu punctum a partir de um vazio.

Pode-se mencionar que parte do studium da peça está em sua plasticidade: formada por figuras geométricas, como triângulos, em parte emoldurados, em parte rompidos por linhas em zigue-zague. Foi confeccionada com miçangas nas cores azul claro, azul escuro, marrom, branco, vermelho e rosa sobre tecido de algodão, arrematado em fios de lã vermelha.

A bolsa tem como pingentes sete moedas enfiadas em linhas de algodão, canutilhos de alpaca, seguis e miçangas azul-marinho, três delas são de cinco centavos da República dos Estados Unidos del Paraguay ${ }^{3}$ e quatro de 100 réis da República dos Estados Unidos do Brasil. A bolsa integra, possivelmente, indumentária dos orixás Xangô e/ou Oxum. Percebe-se que o seu fazer possui influência da arte do bordado com miçanga da República dos Camarões, indumentária do século XIX (ANDRADE, 2014).

É nesta sequência, de sete moedas, que se encontra o punctum. A partir da ausência de uma delas, o pungir acontece e fisga o spectator, como menciona Barthes (1984), levando-o a compreender o contexto a partir do estado gerado, imbricado de história e emoção.

O fisgar constrói no espectator a necessidade de reconstrução do fato, em que a ausência pede uma resposta sobre o sentir. E é nessa tentativa, de responder o punctum como ausência, que é criado o que se chama de representação, que será apresentada a partir do ponto de vista de E. H. Gombrich, Pierre Bourdieu e Jacques Le Goff.
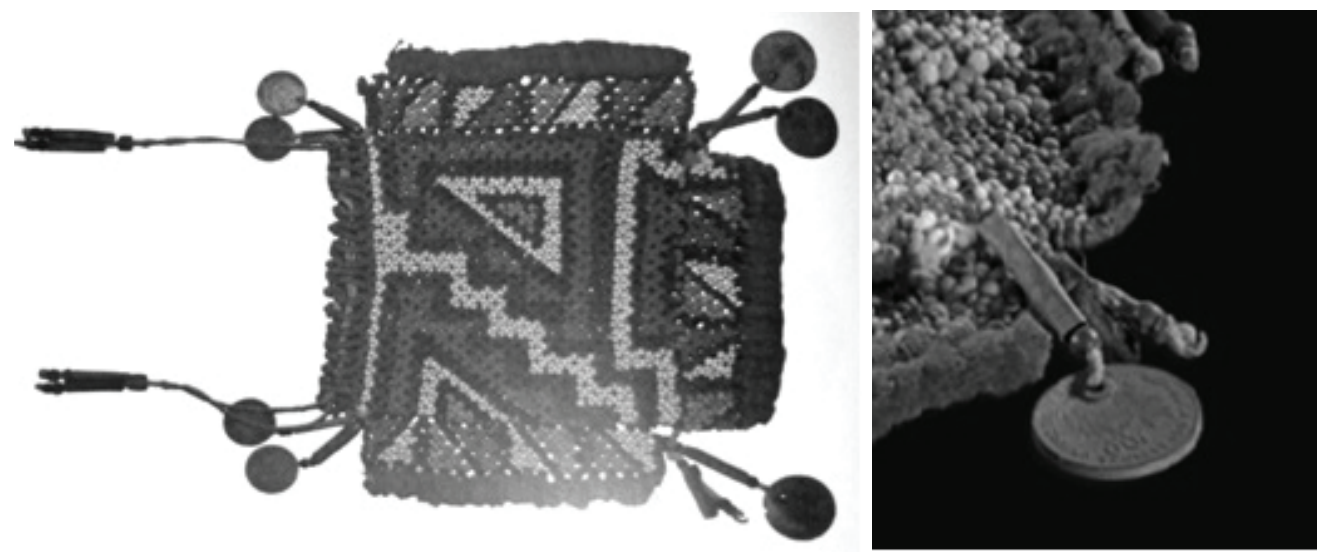
É na visão de Eliane Chiron (1996) que o punctum da peça apresentada se insere. E é sobre o conceito - o qual Icleia Cattani (2005), no artigo O desenho como abismo, menciona - que a artista sente a necessidade de encontrar, em cada desenho, seu punctum. Contrariamente à definição de Barthes (1984), que o situa num detalhe específico, para ela o punctum encontra-se no vazio, no entre dois pontos, entre dois núcleos, descentrado, "corresponde não ao círculo, mas à elipse que possui dois centros e que é a forma barroca por excelência, ou seja, vinculada à ambiguidade, à ambivalência e à tenção" (CATTANI, 2005, p. 24).

Ao trazer a visão crítica de Cattani, sobre o conceito nos desenhos de Eliane Chiron, para a análise do punctum como ausência, na Bolsa tipo Capanga, percebe-se que nesta ausência, como um ponto vazio, mostrado na figura acima, encontra-se um punctum, "onde o olhar se perde como no cruzamento das linhas que compõem o símbolo do infinito", como menciona Cattani (2005, p. 24). Para Chiron (1996), o punctum representa, simultaneamente, abismo e ponto de ancoragem, ponto móvel, jamais fixo, nem estável.

Nesta ideia de ancoragem, abismo e dinamismo, a ausência da oitava moeda da peça desperta a proeza de desvendar a intenção do punctum no outro. O spectator, mesmo conhecendo a história em que surgiu a peça, é remetido para um lugar que contextualiza, de forma subjetiva, a história da falta dessa moeda - falta que proporcionou esse fisgar.

Na experiência vivida por esta ausência, o autor deste artigo perdeu o seu olhar no vazio, que foi preenchido, imediatamente, por metáforas, talvez pelo desejo de saber em que situação aquela moeda foi tirada. Se o artista (não identificado) a tirou propositalmente, querendo correr o risco de jogar-se no abismo e convidar os outros a acompanharem-no, como menciona Cattani (2005), fez do vazio uma nova forma de enxergar a peça. Nesta perspectiva, a Bolsa tipo Capanga deixou de ser apenas uma peça, como parte da Coleção Perseverança, para ser o testemunho de representação de algo inexistente, vivo, e que é ressignificado a cada olhar.

Para alguns teóricos a representação é um conceito amplo e complicado de ser entendido sobre um determinado recorte. Porém, a seguir, apresentam-se algumas formas conceituais, a partir de pressupostos teóricos, que corroboram com a ideia do punctum como ausência e como forma de representação.

Para Le Goff (apud PESAVENTO, 1995, p. 15), representação é a tradução mental de uma realidade exterior percebida e 
se liga ao processo de abstração. $\mathrm{O}$ imaginário faz parte de um campo de representação e, como expressão do pensamento, se manifesta por imagens e discursos que pretendem dar uma definição da realidade. Mas as imagens e discursos sobre o real não são exatamente o real ou, em outras palavras, não são expressões literais da realidade, como um fiel espelho (PESAVENTO, 1995, p. 15).

Para Bourdieu (apud PESAVENTO, 1995, p. 15), as representações mentais envolvem atos de apreciação, de conhecimento e reconhecimento e constituem um campo onde os agentes sociais investem seus interesses e sua bagagem cultural. Esse autor se reporta às cinco estratégias de poder, dizendo que as representações objetuais, expressas em coisas ou atos, são produtos de estratégias de interesse e manipulação:

Ou seja, no domínio da representação, as coisas ditas, pensadas e expressas têm outro sentido além daquele manifesto. Enquanto representação do real, o imaginário é sempre referência a um 'outro' ausente. O imaginário enuncia, se reporta e evoca outra coisa não explícita e não presente. Este processo, portanto, envolve a relação que se estabelece entre significantes (imagens, palavras) com os seus significados (representações e significações). Processo este que envolve uma dimensão simbólica (PESAVENTO, 1995, p. 15).

Sobre esta ausência que desperta o imaginário, Pesavento (1995) reafirma que ela é, pois, representação, evocação, simulação, sentido e significado, jogo de espelhos no qual o 'verdadeiro' e o aparente se mesclam, estranha composição em que a metade visível evoca qualquer coisa de ausente e difícil de perceber. Perseguir a ausência como objeto de estudo é desvendar um segredo, é buscar um significado oculto, encontrar a chave para desfazer a representação de ser e parecer.

Dialogando com Gombrich (1986, p. 89), percebe-se o quanto a ideia de punctum se aproxima da perspectiva representacional, a partir do ausente. Este autor afirma que a arte da representação tem uma história longa e complexa. E exemplifica isso ao mencionar que decifrar a pintura do artista é mobilizar nossas memórias e nossa experiência do mundo visível, e testar a imagem produzida pelos artistas através de projeções e tentativas. Para decifrar o mundo visível como arte, temos que fazer o contrário: mobilizar nossas memórias e nossa experiência das pinturas vistas e testar o motivo outra vez, projetando-as experimentalmente contra o panorama emoldurado. 
Para Gombrich (1999, p. 1):

Representar, lemos ali, pode ser usada no sentido de 'invocar mediante descrição ou retrato ou imaginação, figurar, simular na mente ou pelos sentidos, servir de ou ser tido por aparência de, estar para, ser espécime de, ocupar o lugar de, ser substituto de'. O retrato de um cavalo? Certamente que não. $\mathrm{O}$ substituto para um cavalo? Sim, é isso. Talvez exista nessa fórmula mais do que o olho pode ver.

Ao afirmar ainda que o artista "imita" a "forma exterior" do objeto que está à sua frente, comparamos essa ideia com a de studium - o contexto conhecido e percebido. $\mathrm{O}$ espectador, por seu turno, reconhece por essa "forma”, o "assunto" da obra de arte, que, nesta perspectiva, seria o punctum. A partir do fisgar, outras leituras serão possíveis, contudo, é isso que se poderia chamar a concepção da representação.

\section{Possíveis arremates}

O conceito de punctum, proveniente de Roland Barthes, principalmente da obra A câmara clara (1984), neste artigo, ganhou mais uma interpretação para além dos estudos da fotografia; e o punctum de Eliane Chiron (2013) trouxe a perspectiva de entender o conceito sobre uma visão mais aprofundada sobre seus sentidos e sua função a partir da ideia de ausência.

Barthes nomeou um "detalhe" na foto que chama a atenção daquele que olha - o punctum, enquanto o que me punge, o que me toca. Claro que Barthes (1984) coloca esse conceito enquanto recepção de um olhar na foto, um detalhe expansivo e metonímico que leva o receptor da foto para estados outros. Mas, Eliane Chiron (2013) constrói a relação de fruição dinâmica com o ser poético suscitado em um punctum construído na ideia de vazio, do não estático e do entre.

A ideia de Chiron (2013) suscitou, nesta proposição, pensar o seu conceito, não como elemento metodológico, nem de análise, como apresentado no studium de Barthes (1984), mas como configuração de um ato sensível, que é disparado, quando fisga, e remete o spectador a diferentes situações.

Esse contexto memorativo, despertado pela ausência, foi conectado com a ideia de representação, algo que é configurado a partir das referências culturais do observador pungido, descrita por alguns autores, dentre eles E. H. Gombrich (1999), Pierre Bourdieu e Jacques Le Goff. 
Enquanto o punctum da foto afeta, o punctum como ausência dinamiza. Portanto, o ponto de encontro dinâmico de recriação de uma ação observada na Bolsa tipo Capanga, na ausência de sua oitava medalha, pelo conceito de punctum gerou a ideia de que a representação é enraizada em condições culturais, e que pode ser construída no contexto do fisgar do punctum, percebido em Eliane Chiron (2013). Contudo, nossa posição crítica se intercruza com a de Jacques Lenhardt (2013, p. 7), que resume esta percepção: "para entender o método seguido por Eliane Chiron, devemos seguir as palavras que vêm à mente". Estas imagens, portanto, são geradas no ausente, no vazio, no entre meios e entre dois pontos, que constituem o que se chama representação.

NOTAS

1 Parte do Acervo do Museu do Instituto Histórico e Geográfico de Alagoas - IHGAL. Sua origem está conectada com o "Quebra do Xangô", ato que culminou com a quebra de todos os terreiros de matriz africana, no Estado de Alagoas, em 1912. Os mais de 215 objetos que restaram do quebra-quebra representam a memória, manifestações culturais e a presença negra em terras caetés.

2 Peça pertencente à Coleção Perseverança. Catalogada como parte da indumentária de Orixás. Recebe este nome devido a sua configuração. Pertencia a orixás que possuíam espírito de caça e de aventura, como por exemplo, Ogum.

3 A presença das moedas do Paraguai evidencia a possibilidade de, entre os participantes dos xangôs alagoanos, existir ex-combatentes da Guerra do Paraguai. Alagoas enviou grande contingente de soldados negros que, depois de finalizada a guerra, foram libertados. A guerra do Paraguai, com início em 1864 e término em 1870, foi usada como pretexto para retardar a extinção da escravidão.

\section{Referências}

ANDRADE, Fernando Antônio Gomes de. Legba: a guerra contra o xangô em 1912. Brasília: Senado Federal, Conselho Editorial, 2014.

BARTHES, Roland. A câmara clara. Rio de Janeiro. Nova Fronteira: 1984.

. A câmara clara: nota sobre a fotografia. Rio de Janeiro: Nova Fronteira, 2015.

CATTANI, Icléia. O desenho como abismo. In: Revista Porto Arte, Porto Alegre, v. 13, n. 23, p. 23-30, novembro de 2005.

CHIRON, Eliane. Ao $7^{\circ} \mathrm{X}$ : trivium com centauro, estrelas e dançarinas. In: Revista Porto Arte, Porto Alegre, v. 7, n. 13, p. 7-33, nov. 1996.

. L'énigme du visible. Poiétique des arts visuels. Paris:

Éditions de La Sorbonne/CRAV, 2013. 
GOMBRICH, Ernst H. Arte e ilusão: um estudo da psicologia da representação pictórica. São Paulo: Martins Fontes, 1986.

- Meditações sobre um cavalinho de pau. São Paulo: Edusp, 1999.

HARDY-VALLÉE, Benoit. O que é um conceito? Trad. Marcos Bagno. São Paulo: Parábola, 2013.

IBRI, Ivo Assad. O significado de primeiridade em Schelling, Schopenhauer e Peirce. In: Cognitio, São Paulo, v. 9, n. 2, p. 223-234, jun./dez. 2008.

LENHARDT, Jacques. Préface. In: CHIRON, Eliane. L'énigme $d u$ visible. Poiétique des arts visuels. Paris: Éditions de La Sorbonne/CRAV, 2013.

PEIRCE, Charles Sanders. The collected papers of Charles Sanders Peirce. Disponível em: <https://colorysemiotica. files.wordpress.com/2014/o8/peirce-collectedpapers.pdf> Acesso em: 4 jul. 2018

PESAVENTO, Sandra J. Em busca de uma outra história: imaginando o imaginário. Revista Brasileira de História, São Paulo, v. 15, n. 29, p. 9-27, 1995.

VELHO, Gilberto; VIVEIROS DE CASTRO, Eduardo. O conceito de cultura e o estudo das sociedades complexas. Espaço: cadernos de cultura, v. 2, p. 11-26, 1980.

Recebido em: 30/07/2017

Aceito em: 14/05/2018 


\section{ANDERSON DIEGO ALMEIDA CORREIO \\ andersondiego.almeida@yahoo.com.br}

Doutorando em Artes Visuais: História, Teoria e Crítica de Arte - Universidade Federal do Rio Grande do Sul - PPGAV/UFRGS. Mestre em História, Graduado em Design e Arte. Pesquisador das temáticas: história e arte afro-brasileira, Etnodesign, museologia da arte, memória e representação da arte e do design.

\section{FRANCISCO MARSHALL CORREIO}

marshall@ufrgs.br

Professor e Historiador nos programas de Pós-Graduação em Artes Visuais, PPGAV, e História, PPGH, ambos na Universidade Federal do Rio Grande do Sul - UFRGS. 